\title{
The Projection of Iran's Healthcare Expenditures By 2030: Evidence of a Time-Series Analysis
}

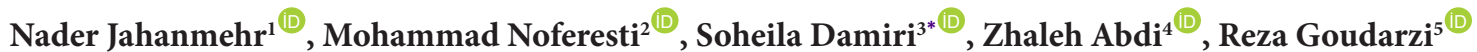

\begin{abstract}
Background: The projection of levels and composition of financial resources for the healthcare expenditure (HCE) and relevant trends can provide a basis for future health financing reforms. This study aimed to project Iran's HCEs by the sources of funds until 2030

Methods: The structural macro-econometric modeling in the EViews 9 software was employed to simulate and project Iran's HCE by the sources of funds (government health expenditure [GHCE], social security organization health expenditure [SOHCE], out-of-pocket [OOP] payments, and prepaid private health expenditure [PPHCE]). The behavioral equations were estimated by autoregressive distributed lag (ARDL) approach.

Results: If there is a 5\%-increase in Iran's oil revenues, the mean growth rate of gross domestic product (GDP) is about $2 \%$ until 2030. By this scenario, the total HCE (THCE), GHCE, SOHCE, OOP, and PPHCE increases about 30.5\%, 25.9\%, $34.4 \%, 31.2 \%$, and $33.9 \%$, respectively. Therefore, the THCE as a percentage of the GDP will increase from $9.6 \%$ in 2016 to $10.7 \%$ in 2030 . It is predicted that Iran's THCE will cover $22.2 \%, 23.3 \%, 40 \%$, and $14.5 \%$ by the government, social security organization (SSO), households OOP, and other private sources, respectively, in 2030.

Conclusion: Until 2030, Iran's health expenditures will grow faster than the GDP, government revenues, and non-health spending. Despite the increase in GHCE and total government expenditure, the share of the GHCE from THCE has a decreasing trend. OOP payments remain among the major sources of financing for Iran's HCE.

Keywords: Health Expenditure, Health Insurance, Public Health Expenditure, Out-of-Pocket Payment, Health Financing, Iran

Copyright: @ 2022 The Author(s); Published by Kerman University of Medical Sciences. This is an open-access article distributed under the terms of the Creative Commons Attribution License (https://creativecommons.org/licenses/ by/4.0), which permits unrestricted use, distribution, and reproduction in any medium, provided the original work is properly cited.

Citation: Jahanmehr N, Noferesti M, Damiri S, Abdi Z, Goudarzi R. The projection of Iran's healthcare expenditures by 2030: evidence of a time-series analysis. Int J Health Policy Manag. 2022;11(11):2563-2573. doi:10.34172/ijhpm.2022.5405
\end{abstract}

Article History:

Received: 3 September 2020 Accepted: 3 Jnauary 2022 ePublished: 1 February 2022

\section{Key Messages}

Implications for policy makers

- Until 2030, the growth rate of health expenditures will be higher than the gross domestic product (GDP) and government revenues and expenditures.

- Government resources will not adapt to the rapid growth of health expenditures, and the government's share in financing health expenditures will decrease.

- If the current trends continue, the Iranian health system will not successfully reduce the share of out-of-pocket (OOP) payments to less than $30 \%$ in the medium term (until 2030).

- Policy-makers should give special attention to efforts to slow the growth rate of health spending and efficient resource management.

- To avoid the impact of financial and economic crises on population health, financing policies should move towards options that ensure system resilience.

Implications for the public

All countries are working to ensure universal access to healthcare. Health financing system reform is the backbone of all efforts to achieve this goal. A correct understanding of the current level and composition of healthcare costs and their future direction is a useful guide to appropriate policies in this area. Over the next few years, health expenditure will grow faster than local incomes, threatening the stability of the healthcare financial system, government finances, and economic stability. In this situation, improving the efficiency of the health system and resource management should be pursued more seriously. In this situation, improving the efficiency of the health system and resource management can lead to increased compliance between revenue growth rates and expenditure growth rates and maintaining the stability of the health sector financial system. 


\section{Background}

The healthcare system is one of the determinants of health that participates with other factors in promoting population health. Without healthcare, there are many lost opportunities for significant improvements in population health. ${ }^{1}$ Therefore, guaranteeing the public access to necessary health services without any financial hardship - universal health coverage (UHC) - is put on top of the 2030 Agenda for Sustainable Development Goals.,3 Achieve UHC requires robust healthcare systems with good governance and sustainable financing. ${ }^{4}$

Health financing concerns mobilization, accumulation, and allocation of money to cover healthcare needs. ${ }^{5}$ The fairly and effective mobilization of sufficient and sustainable financial resources for the health sector is the most significant purpose of health financing systems. ${ }^{6}$ However, the health policymakers encounter to increase the challenges in achieving these goals around the world. ${ }^{7}$ The countries deal with the challenge of sufficient resources mobilization for health financing. ${ }^{8}$ Estimations indicate that out-of-pocket (OOP) payments are important in health financing, particularly among low- and middle-income countries. It is predicted to remain the main source of total healthcare expenditure (THCE) financing. These values are $12.7 \%, 29.6 \%, 51.2 \%$, and $39.2 \%$ in high-income, upper-middle-income, lower-middleincome, and low-income countries, respectively, until 2050. In Iran, OOP payment was $37.6 \%$ in 2016 and $38.9 \%$ in $2050 .{ }^{9}$ Increased health expenditure along with an increased share of the THCE from gross domestic product (GDP) due to factors including technological advancement, demographic transition, increased expectations of consumers, and resources limitations resulted in the inability or unwillingness of the governments to increase spending on healthcare services which may threaten sustainable financing of health systems in the future. ${ }^{10}$

Improving the equity in health financing and financial protection was emphasized in Iran's national developmental programs ${ }^{11-16}$ which was supported by numerous policies such as insurance program for patients on a hospital bed, free treatment of the victims of traffic accidents, development of the family physician program and rural insurance program, the establishment of boards of trustees in educational hospitals, and full-time geographical programs of physicians ${ }^{17}$. The Health Transformation Plan (HTP), which was launched in 2014, also sought to provide financial protection against health expenditures. HTP was funded through government resources, including a $59 \%$ increase in the annual budget of the Ministry of Health and Medical Education, the allocation of $10 \%$ of the resources obtained from the targeted subsidy plan, and $1 \%$ of value-added tax revenue to the health sector. However, Iran's recent economic recession (difficulty selling oil due to imposed sanctions and the fluctuation of oil price) has prevented the full implementation of HTP. In other words, not receiving the approved budget by the public health insurance schemes imposed a massive debt on the health centers, so that the Ministry of Health and Medical Education was ordered to increase further the efficiency of health spending. ${ }^{18,19}$ Despite all these efforts, the evidence shows that financial protection has not yet been achieved among the Iranian population. ${ }^{20,21}$

The fiscal space for health reflects the government's ability to increase health expenditure without any prejudice to the sustainability of its financial position. It depends on a suitable macroeconomic environment characterized by sustainable economic growth and low budget deficit. ${ }^{22}$ Nevertheless, the challenges such as severe economic fluctuations, ${ }^{23}$ the budget's dependence on oil revenue, ${ }^{24,25}$ low tax efforts, ${ }^{26}$ imposed economic sanctions, ${ }^{27}$ an increasing budget deficiency, ${ }^{28}$ and other factors barriers to expanding fiscal space for health in Iran. For instance, the United States' new sanctions have decreased Iran's economic growth rate from 3.7\% in 2017 to $-4.8 \%$ in $2018 .{ }^{29}$ The failure of policies aims to improve financial protection, and the increasing growth of health expenditure and the above-mentioned economic problems can encounter Iran with many challenges to achieve the UHC in future. Up to the past three decades, the health expenditure has rapidly grown in many countries, including Iran, which are crucial concerns for policy-makers, patients, and insurance companies. ${ }^{30-32}$ From 1995 to 2016, the annual $\mathrm{HCE}$ increased by $4 \%$ worldwide from 3.5 to 8 trillion dollars. ${ }^{33}$ Iran's healthcare expenditure (HCE) increased from 7 to 34 billion dollars during these 21 years, becoming 4.8 times larger. ${ }^{33-47}$ Policy-makers across the globe are concerned about the financial sustainability of public expenditure, increasing price of healthcare services, health sector, and financial pressures on patients and their families; therefore, they seek several ways to assess the extent of these problems and to develop political reform plan to reduce the pressure of growing costs. ${ }^{48}$ Such concerns have motivated the design of various models for predicting health expenditure in many countries. $^{33,35-47}$ Predicting HCE and its funding sources are vital for effective policy-making in the health sector. ${ }^{36}$ The correct perception of the level and compositions of the resources for financing HCE and its trend over time can act as the basis for future health financing policy formulation. ${ }^{49}$ Considering this background, this study aimed to project Iran's health expenditure until 2030.

\section{Methods}

Data

A structural macro-econometrics model was employed to simulate and project Iran's HCE. The THCE was divided into two components, ie, public health expenditure (including the government health expenditure [GHCE] and social security organization health expenditure [SOHCE]) and the private health expenditure (including OOP payments and prepaid private health expenditure [PPHCE]). For selecting the variables, we first reviewed the existing studies on the determinants of health expenditures and studies conducted to predict health expenditures. A set of variables was extracted and evaluated in several meetings of the research team members, and the variables that seemed appropriate to the study's objectives entered the modeling process. Finally, in addition to the health expenditure variables, a wide range of variables, including economic, government revenue and expenditure, population variables, and health insurance 
variables employed to develop the structural macro model. The annual time series data of variables, extracted from the different databases such as Central Bank of the Islamic Republic of Iran, Statistical Center of Iran, statistical reports of the social security organization (SSO), statistical reports of the Central Insurance of Iran, and annual budget laws. additional information about data source of each variable are provided in Table S1 (see Supplementary file 1). However, some variables data were available from 1959. Since other data were unavailable, the final model was simulated on the data related to 1991-2016.

\section{Econometrics Model}

The macro-structural econometric model used in this study, which is a kind of simultaneous equations system, was created in the following steps by EViews 9 software:

1. Determining the variables co-integration rank: If the time series variables used in estimating model coefficients are not stationary, the result may be a spurious regression. In econometrics, co-integration helps estimate a regression due to the levels of variables without any spurious regression. The concept of cointegration means two or more variables of a time series are linked to show a long-run equilibrium relationship. However, the time series itself might be unstable. They follow each other so well when their difference is stable. The augmented Dicky-Fuller test was used to analyze the stationarity of variables. The results of this test are presented in Table S2 (see Supplementary file 2).

2. Estimating the coefficients: The behavioral equations of the model were estimated due to autoregressive distributed lag (ARDL) method. ARDLs are standard least-squares regressions, which include the lags of both the dependent variable and explanatory variables as regressors. For instance, when the research goal is to estimate a long-term equilibrium relationship between $\mathrm{Y}, \mathrm{X}$, and $\mathrm{Z}$, the corresponding $\mathrm{ARDL}$ technique is defined as follows:

$\mathrm{Y}_{\mathrm{t}}=\alpha_{0}+\sum_{J=1}^{P} \alpha_{\mathrm{j}} \mathrm{Y}_{\mathrm{t}-\mathrm{j}}+\sum_{J=1}^{Q 1} \beta_{1 \mathrm{j}} \mathrm{X}_{\mathrm{t}-\mathrm{j}}+\sum_{J=1}^{Q 2} \beta_{2 \mathrm{j}} \mathrm{Z}_{\mathrm{t}-\mathrm{j}}+\mathrm{V}_{\mathrm{t}}$

3. Conducing Banerjee, Dolado, and Master tests: In ARDL equations, if the sum of coefficients of lag variables of the dependent variable is smaller than 1 ( $\left.\sum_{i=1} a_{i}<1\right)$, the dynamic model is inclined towards the long-run equilibrium model. Therefore, the following hypotheses are tested for the co-integration test.

$\mathrm{H}_{0}: \sum_{i=1}^{\rho} a_{i}-1 \geq 0$

$\mathrm{H}_{1}: \sum_{i=1}^{\rho} a_{i}-1<0$

Equation 2. Hypotheses of the Co-Integration Test

The following equation calculates the $\mathrm{t}$-statistic required to conduct the above test:

$$
\begin{aligned}
& \mathrm{t}=\frac{\sum_{i=1}^{P} \hat{a}_{i}-1}{\sum_{i=1}^{\rho} s_{\widehat{a}_{i}}} \\
& \text { Equation 3. The Co-Integration Test Statistic }
\end{aligned}
$$

These statistics should be negative to confirm the existence of a long-run relationship. Its absolute value should be greater than the absolute value of critical quantity proposed by Banerjee, Dolado, and Master (1992).

4. Estimating the error correction model of each equation: If a long-run relationship is confirmed in ARDL equations, then it is possible to observe estimations of short-term and long-term relationships and the error correction coefficient of each equation in each equation in EViews 9 software. This error correction coefficient shows the speed of movement towards equilibrium.

5. Assumptions of the classical linear regression model assessment: Four tests of Jarque-Bera, BreuschGodfrey, White, and Ramsey tests were utilized to check the normality of error terms distribution, lack of serial correlation between error terms and other variables, homoscedasticity of error term and accuracy of functional form specification, respectively.

6. Testing the Interactive performance of long-term equilibrium and short-term dynamisity relationships: To develop a model, each of the estimated equations should have enough conceptual and statistical validity and interact appropriately with each other. In other words, in-sample simulation results of a model should adequately match the historical trend of variables included in the model. Therefore, the dynamic simulation was performed by putting each estimated equation next to other model equations. Then, the root mean square error (RMSE) and the Utile index are employed to analyze the proximity of trends in generated variables to their historical trend. When the equation performance was evaluated inappropriate simulation, its specification was revised, and the model was again estimated using the ARDL technique. This process was repeated until it was possible to obtain a series of valid equations presenting acceptable simulation results. Then, this model was used for prediction. Demographic variables, urbanization rate, and oil revenues were considered exogenous in the adjusted model. The predictions of demographic variables were extracted from the world population prospect 2017 made by United Nations. ${ }^{50}$ Since oil revenues are affected by different national and international variables such as global supply and demand for oil, its prediction is complicated and beyond this research scope. Hence, the variable was considered exogenous compared to the equations system to analyze its effect based on scenario making. Various scenarios could be considered for the growth rate of Iran's oil and gas revenues, including the growth rate of these revenues in the years after the Iran-Iraq war, the growth rate in the last 10 to 15 years, and any other possible scenario. However, this study uses predictions made by US Energy Information Administration. ${ }^{51,52}$ The average growth rate of $4.39 \%$ was predicted for the global oil price from 2016 to 2030 .

Results

This study aims to project Iran's HCE until 2030 through a macro-econometrics model. The parameters of the 
equations included in this model, the standard deviation of the parameters, and other characteristics of the equations specified are presented in Supplementary file 3. Final developed dynamic macro-structural econometric model, the process of evaluating the validity of this model and related information is provided in Supplementary file 4 .

Figure 1 shows the simulation of HCE variables, the values of Utile indices (U), and the RMSE of their simulation. The model can simulate the trend of variables well. Utile indices and the RMSE for other simulated variables are presented in Table S44 (see Supplementary file 4).

Table indicates the predictions of HCE variables, GDP, and the government's revenues and expenditures. Hence, under the scenario of a $5 \%$ increase in oil revenues, it is predicted that the total HCE of 2030 will be 46 times larger than that of 2016. Indeed, it increased to 55547040000.00 million rials in 2030 from 1209785292.00 million rials in 2016. If the prediction is due to the fixed prices of 2004, then the THCE of the period will be 1.8 times larger and increase from 115990919.70 to 216207345.90 million rials.

If the current situation continues, public healthcare costs are expected to grow steadily over the next few years, and the proportion of private healthcare costs is projected to remain higher than other sources of funding. Indeed, the share of
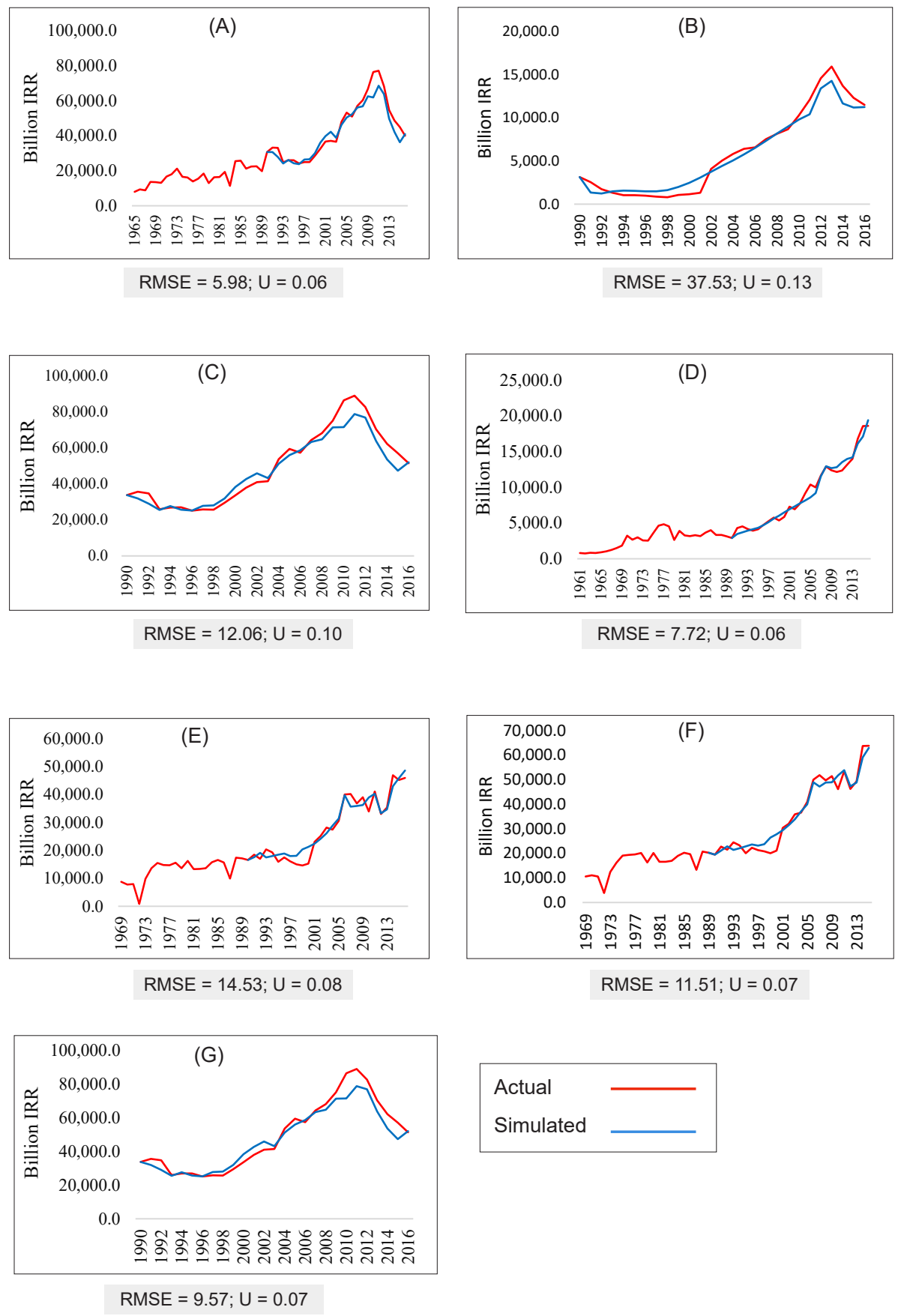

Figure 1. The Simulation of Iran's Health Expenditure Variables in the Equations System: (A) Out-of-pocket health expenditure, (B) prepaid private health expenditure, (C) Private health expenditure, (D) Social Security Organization health expenditure, (E) government health expenditure, (F) Public health expenditure, (G) total health expenditure. Abbreviation: RMSE, root mean square error. 
Table. The Health Expenditure Predicted for 20212026 and 2030

\begin{tabular}{|c|c|c|c|c|c|c|c|c|c|}
\hline & \multicolumn{2}{|c|}{2016 (Million IRR) } & \multicolumn{2}{|c|}{ 2021(Million IRR) } & \multicolumn{2}{|c|}{2026 (Million IRR) } & \multicolumn{2}{|c|}{2030 (Million IRR) } & \multirow{2}{*}{$\begin{array}{l}\text { Annualized Rate of } \\
\text { Change (2016-2030) }\end{array}$} \\
\hline & Current Price & Constant Price (2003) & Current Price & Constant Price (2003) & Current Price & Constant Price (2003) & Current Price & Constant Price (2003) & \\
\hline THCE & 1209785292.00 & 115990919.70 & 5264794000.00 & 162611334.40 & 19201540000.00 & 194552323.40 & 55547040000.00 & 216207345.90 & 30.5 \\
\hline Public health expenditure & 672807820.50 & 64506981.83 & 2242962000.00 & 69277362.78 & 8197621000.00 & 83059286.48 & 25310930000.00 & 98518462.87 & 29.6 \\
\hline GHCE & 478761811.50 & 45902378.86 & 1424433000.00 & 43995824.14 & 4485271000.00 & 45445307.72 & 12354780000.00 & 48088866.54 & 25.9 \\
\hline Private health expenditure & 536977471.50 & 51483937.83 & 3021832000.00 & 93333971.66 & 11003920000.00 & 111493047.00 & 30236110000.00 & 117688883.00 & 33.5 \\
\hline OOP health expenditure & 417001771.40 & 39980994.38 & 2476178000.00 & 76480600.93 & 8596440000.00 & 87100168.78 & 22221760000.00 & 86494397.38 & 31.2 \\
\hline PPHCE & 119975700.10 & 11502943.44 & 545654800.00 & 16853395.44 & 2407480000.00 & 24392878.25 & 8014355000.00 & 31194505.12 & 33.9 \\
\hline
\end{tabular}

Abbreviations: THCE, total healthcare expenditure; GHCE, government health expenditure; SOHCE, social security organization health expenditure; OOP, out-of-pocket; PPHCE, prepaid private health expenditure. 
public and private spending of total HCE will be $45.56 \%$ and $54.43 \%$, respectively, in 2030. GHCE, the SOHCE, OOP, and PPHCE will cover $22.24 \%, 23.32 \%, 40 \%$, and $14.53 \%$ of the THCE, respectively, in 2030 (Figure 2).

The average growth rate of THCE will be nearly $4 \%$ since 2020 , greater than the average GDP growth rate, approximately $2 \%$. The THCE to GDP ratio will experience a descending trend reaching $9 \%$ in 2020 from $9.6 \%$ in 2016. Then, with an increasing trend, it reaches $10.76 \%$ in 2030 (Figure 3).

Although the annual budget deficit will rise in the coming years, Iran's government will cover a larger HCE share. The share of HCE from the total government's expenditures will increase from nearly $19.2 \%$ in 2016 to $22 \%$ in 2030 . However, since HCE grows faster than the government's total expenditures, the ratio of GHCE to the THCE will gradually decrease and reach nearly $22.2 \%$ in 2030 from $35.5 \%$ in 2016 (Figure 4).
Discussion

This study was conducted to project Iran's HCE concerning macroeconomic conditions. Due to the results, if Iran's oil revenues increase by $5 \%$, THCE is 46 times greater in 2030 than in 2016 at current prices. Iran's high inflation rate primarily causes this rapid growth. After adjusting for the inflation rate, HCE grows 1.8 times over the period by constant prices. Due to the results of Institute for Health Metrics and Evaluation study, Iran's THCE (purchasing power parity \$ 2017) will increase from \$109766045 in 2016 to \$183223156 in 2030. In other words, it becomes 1.66 times larger ${ }^{53}$ a finding which is slightly different from the results of our study.

As mentioned earlier, there is a significant difference between the HCE of nominal prices and that of actual prices in Iran due to the high inflation rate. Inflation is a sustained increase in the general price of goods and services in an economy over time..$^{54}$ Inflation sustainability is a fundamental feature of Iran's economy. ${ }^{55}$ In inflation conditions, some

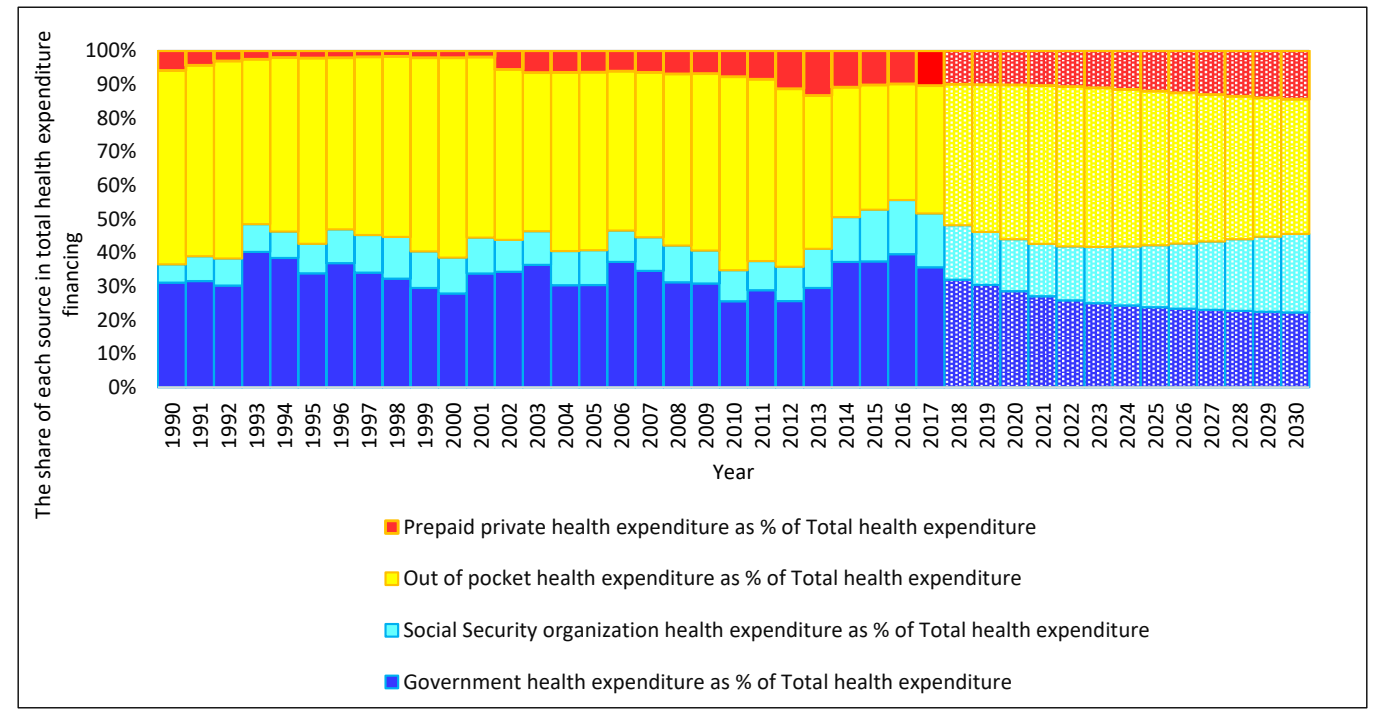

Figure 2. The Trend in Shares of Financing Factors in Iran's Health Expenditure Coverage (1990-2030).

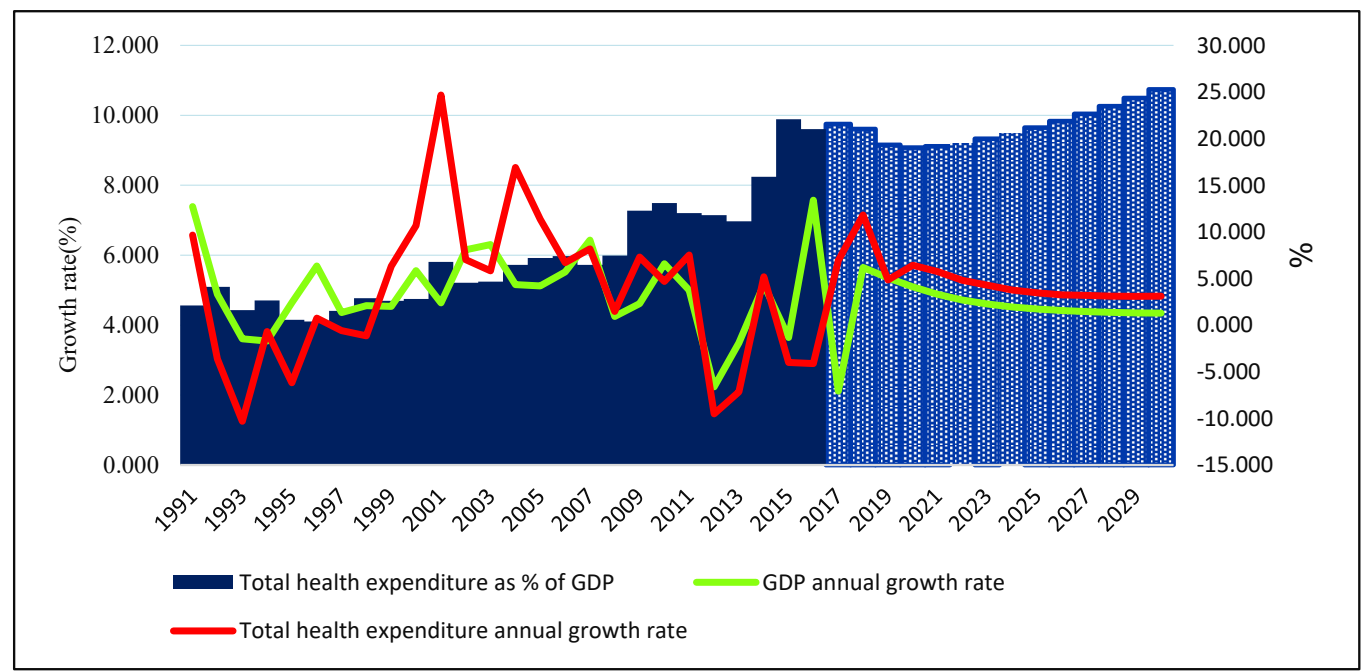

Figure 3. Previous Trend and Future Values of Health Expenditure as a Percentage of GDP (Right Side); Comparison of Health Expenditure Growth Rate With GDP Growth Rate (Left Side). Abbreviation: GDP, gross domestic product. 


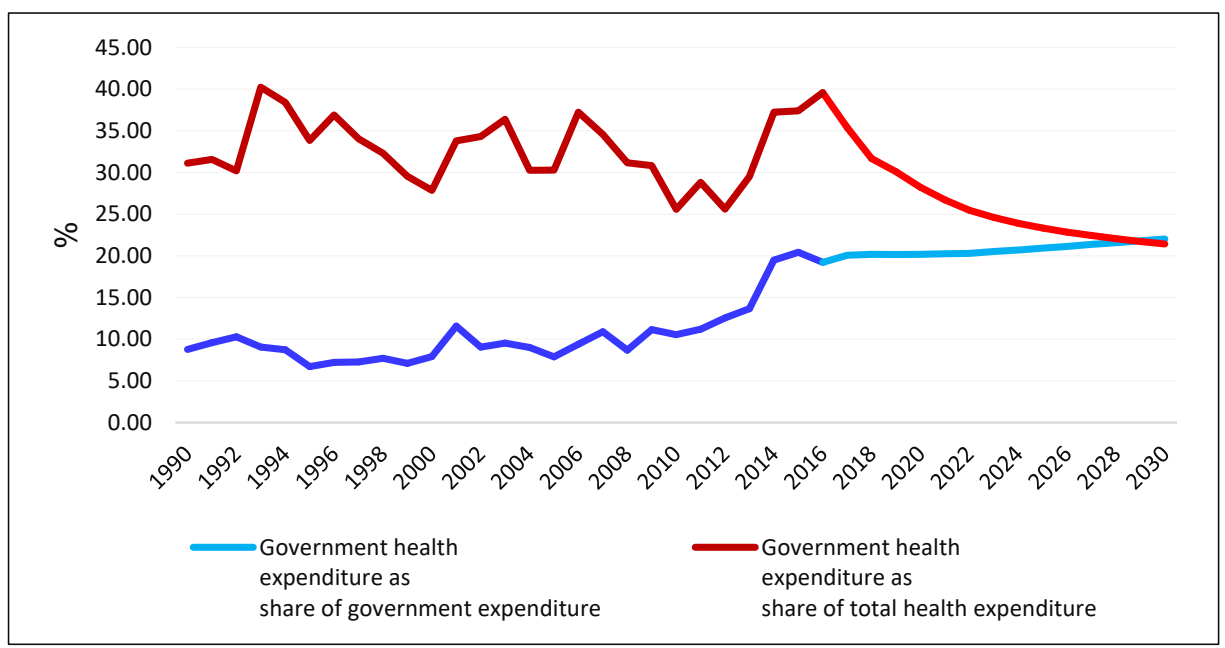

Figure 4. Iran's Government Health Expenditure as a Percentage of Total Government Expenditure and Total Healthcare Expenditure.

population groups with fixed incomes lose their purchasing power and become poorer. The persistence of these conditions, especially in developing countries like Iran, will increase income inequality. In the health sector, this inequality will have many adverse effects, such as the increased chances of families encountering catastrophic health expenditures because of the nature of the market and - inelasticity of demand for healthcare. ${ }^{56,57}$ According to the Central Bank of the Islamic Republic of Iran, the health sector's inflation is even higher than the general inflation. ${ }^{57}$ However, it should be noted that Iran is not the only country where inflation is higher in the healthcare sector than the general inflation, which is also true about other countries. ${ }^{54,58}$

Nowadays, developed countries encounter the challenge of an increased HCE to GDP ratio, which has increasingly been worrying policy-makers of such countries..$^{59}$ Our results show that as a percentage of GDP, HCE increases from 9.6\% in 2016 to $10.76 \%$ in 2030 because HCE grows faster than GDP. Over the past 15 years, the global health economy has experienced annual growth of $4 \%$ on average compared to the global economy with an average growth rate of $2.8 \%{ }^{49}$ Because of the increase in per-capita income and economic growth, people spend most of their income to increase welfare by spending in the service sector. Health is an integral part of these services, which are considered. ${ }^{60}$ The global HCE will be $8 \%$ of GDP on average in 2030. This increase was predicted to be from $6.1 \%$ to $12.6 \%$ (with an average of $8.8 \%$ ) for Iran, ${ }^{53}$ consistent with our study findings. When HCE growth outpaces GDP growth, national economic sustainability may be weakened. ${ }^{10}$ Therefore, these findings can remind the policy-makers of the necessity of adopting specific approaches to curb HCE. Adopting appropriate policies to reduce the growth of HCE requires identifying major cost drivers first. ${ }^{61}$ The growth of HCE is caused by population growth, income per capita, inflation, and the excess growth of HCE due to the development of health technologies and increased expectations of patients. The excess growth is responsible for increased HCE as a percentage of GDP, which challenges financial sustainability, the primary cause of the increase in HCE observed in the US since the late 1950s. After a few decades, such a growth rate has started in many low- and middle-income countries such as Iran on a much smaller scale. ${ }^{62}$ Some of the main factors driving the growth of Iran's HCE included an increase in income per capita, literacy rate, urbanization rate, and physicians. ${ }^{63}$ Some of the actions which were taken in Iran in recent decades to control costs and improve efficiency extend the primary healthcare network, develop a health expenditure monitoring system through the insurance mechanism, implement the family physician plan, establish the rural health insurance and referral system in rural areas and towns with fewer than 20000 people, implement the hospital authority plan, merging some essential insurance funds into the Iran Health Insurance Organization, ${ }^{64}$ and establishing National Plan for Health Technology assessment ${ }^{65}$ However, there is a long way to go to achieve the desired results of these plans.

Although public funds are the cornerstone of sustainable financing for UHC in most countries, ${ }^{66}$ the predictions show that sharing the public spending in HCE financing slightly changes in future. In general, the shock caused by increased public expenditure due to the implementation of HTP, implemented in 2014, will wear off, and the public sector's share of HCE financing will decrease. The government tries to play a more significant role in health system financing; therefore, GHCE as a percentage of total government expenditure increases from $19.2 \%$ to $22 \%$. However, since HCE (31.49\%) grows faster than government revenues $(25.27 \%)$ and expenditures $(24.9 \%)$, the share of GHCE from THCE decreases from $39.5 \%$ in 2016 to 22.24 in 2030 . In recent years, the concept of fiscal space for health, whether the government can allocate additional resources to the health sector without prejudicing its financial sustainability, has grabbed much attention..$^{67}$ The expansion of Fiscal space for health depends on favorable macro-economic environments, including sustained economic growth, high revenue mobilization capacity, and low levels of fiscal deficits. ${ }^{22}$ Using a macro-fiscal framework, our results imply that Iran's government had limited fiscal space for health. According to the estimations, government expenditure will be higher than its revenues in the future, and Iran's budget deficit will increase the following trends. Due to the International Monetary Fund, Iran's budget deficit lasts 
until 2023. ${ }^{68}$ Based on a report published by the Research Center of Parliament, to increase economic sustainability, any budgetary commitment should be considered carefully in the future. ${ }^{69}$ Hence, financial sustainability should not be neglected to impose higher health expenditures on the government budget. The main drivers of fiscal space for the health sector can be classified into five categories: favorable macroeconomic conditions, reprioritizing the budget towards health, earmarked funds, development assistance for health, ${ }^{49}$ and efficiency gains..$^{70,71}$ Considering several factors, including the decreasing trend of development assistance for health for the upper-middle-income countries, ${ }^{34}$ unsuitable macroeconomic conditions of Iran, the limited potential to increase fiscal space for health through increasing health sector budget due to macroeconomic conditions, it seems that the best midterm options to expend the fiscal space for health are cost management and efficiency improvement. Although several studies evaluated the capacity of earmarking in the expansion of fiscal space for health as moderate, ${ }^{72}$ there is insufficient evidence for judging the financial capacity of this option in Iran; thus, further research is needed.

Iran has had a health insurance system since 1947 of which has significantly developed. The SSO, Armed Forces Insurance, Iran's Health Insurance, and Imam Khomeini Relief Foundation are now Iran's major health insurance pools. ${ }^{73}$ In their study, Davari et al classified Iran's health insurance system challenges as several categories, including increased growth of health expenditure, lack of systematic assessment of health technology, the limitations of financial resources, managerial challenges, regulation challenges, and the high number of uninsured individuals. ${ }^{74}$ Iran's health insurance system could not achieve a universal insurance coverage in terms of specific reasons such as unknown insured rate, regressive financing, and non-transparent financial flow, fragmented and noncompulsory system, non-scientifically designed benefits package, non-health-oriented and expensive payment system; uncontrolled demands, and the administrative deficiency. ${ }^{75}$ Due to data limitations, it was impossible to simulate and project the expenditure growth of each health insurance scheme separately. Since Armed Forces Insurance, Iran's Health Insurance, and the Imam Khomeini Relief Foundation receive a budget from the central government, their health expenditure growth rates were predicted under GHCE, and only SSO was estimated separately.

Due to the estimations, sharing SSO spending from THCE increases from $16.03 \%$ in 2016 to $23.32 \%$ in 2030 . However, other studies show that SSO financial condition is not promising. For instance, the reports published by the Research Center of the Islamic parliament showed that SSO would face financial crises in the near future. ${ }^{76}$ If so, Iran's government will lack the financial resources required to support; as a result, there is a concern that a considerable portion of the financial burden of health expenditure is imposed on the private sector, including households.

Sharing the private funds from THCE increases in future. The private expenditure consists of households (OOP), firms, non-profit organizations, private medical insurance schemes, and other private sector organizations which are collectively projected in the form of PPHCE. Due to the estimations, OOP as a percentage of THCE increased from $34.4 \%$ in 2016 to $40 \%$ in 2030 . Projected OOP payments will be lower than those after the implementation of HTP; however, it exceeds OOP payments during the 2014-2016 period. Nevertheless, the predictions show that sharing the OOP payments of private spending decreases from $77.65 \%$ in 2016 to $73.49 \%$ in 2030, and the PPHCE of health financing will increase. The findings conducted by Institute for Health Metrics and Evaluation confirm the occurrence of this pattern in Iran's health system. ${ }^{53}$ In 2016 , nearly $58.6 \%$ of this item came from private medical insurance companies. The debate in the international health community on the role of private coverage has often been characterized by an easy dismissal of private insurance as fundamentally undesirable and destined to erode equity and efficiency in healthcare. ${ }^{77}$ The lack of an effective health financing system has become among the most critical issues, especially in underdeveloped countries. The high proportion of OOP payments is an ineffective health financing system. Private health insurance can support families by distributing health risks among many people and protecting them from incurring catastrophic health expenditures. ${ }^{78}$ The evidence shows that private insurance can play a positive role in promoting equity and accessibility in developing countries that are managed in a good manner. ${ }^{79}$ There is a wide range of tools and experiences to regulate the private health insurance market, using which this financing mechanism will be able to play a positive role in developing equitable health system. positive equitable health systems. Policy-makers should actively understand the value of these tools and employ them to serve the needs of the public. ${ }^{77}$

THCE can be predicted from different perspectives. For instance, it can be predicted to focus on diseases, different age groups, services, and functions. However, this study analyzed the ability of each primary source of financing for healthcare which its results may be used as a basis for any health financing reform to accelerate achieving UHC. Hence, it seems that all financing sources should be considered to have a comprehensive evaluation of Iran's health system's future status. At the same time, future studies should focus on designing a sustainable system for health financing and increasing the system's resilience against potential economic shocks to prevent the adverse effects of different crises such as economic sanctions and recessions on public health.

This study has several limitations which should be mentioned. At first, due to data limitations, it was impossible to project the changes in all sources of health financing in detail, so all financing sources were divided into four main groups (government, SSO, households, and other private agents), and forecasts are provided for these four major groups. Second, the necessary data were collected from various sources. Although the statistical caliber of these databases may be inconsistent, it should be noted that there are usually different institutions for data collection and reporting at the national and international levels, depending on the nature of a variable. Therefore, the diversity of databases is not unique to our study. For example, there has been this diversity in the study by Dieleman et al. ${ }^{36}$ It is hoped that improving databases 
such as National Health Accounts will provide a complete set of time-series data to perform more accurate evaluations in the future. Due to the unavailability of data, the simulation was conducted until 2016 (before the sanctions), and it was impossible to analyze the effect of the recent sanction shock. Fourth, despite the considerable role of oil and gas revenue in total government revenue, it was impossible to predict it due to the high complexity of the oil market worldwide. Therefore, oil revenue was considered exogenous in the developed model, assuming a 5\% annual growth. Another limitation of this study is that it does not consider health outcome variables such as life expectancy, maternal mortality, infant mortality, non-communicable and other diseases burden. The explanatory variables of this study have often been economic and reflect the capacity of the Iranian economy to spend in the health system, but it does not reflect how much this expenditure should be given to the overall goals of the health sector. In some studies, the minimum sample size for ARDL is often considered to be 30 observations. In estimating most of the equations designed in this study, the sample size was more than 30 observations. For example, 58 observations were used in estimating the GDP equation. Due to data limitations on variables such as prepaid folk medical costs, its ARDL equation was estimated based on 26 observations, limiting the simulation of the entire macrostructure model based on 26 data points. The cost management and efficient use of existing resources should seriously be considered. It is also necessary to evaluate the government's capacity to expand fiscal space for health in the mid-term so that the health financing system can move towards more sustainability. Since private health insurances are likely to grow, appropriate regulatory strategies should also be developed to control the health insurance market to take advantage of their capacities appropriately and improve the population's health.

\section{Conclusion}

To conclude, due to our findings, until 2030, Iran's HCE grows faster than GDP and government revenue and expenditure. Despite the increased proportion of Iran's GHCE to the total government expenditure, it experiences a descending trend as a percentage of THCE; therefore, efforts to increase efficiency and control costs to match the growth rate of health expenditures with GDP and government financial capacity can be of significant importance in ensuring sustainable health financing. OOP payments will still be a significant source of THCE financing. Sharing PPHCE and SOHCE increases in health financing. Hence, the government and public and private insurance systems should make the reforms to guarantee access to necessary healthcare services of favorable quality, decrease OOP payments, and increase financial protection among households.

\section{Ethical issues}

Ethical approval for the research was received from the Shahid Beheshti University of Medical Sciences with approval code IR.SBMU.PHNS. REC.1396.80.

Competing interests

Authors declare that they have no competing interests.
Authors' contributions

All authors have contributed to this study. Conception and design (NJ, SD, MN, $\mathrm{RG}$ ); Acquisition of data (NJ, SD, MN, ZA); Analysis and interpretation of data (MN, NJ, SD); Drafting of the manuscript (SD, NJ, ZA, RG); Critical revision of the manuscript for important intellectual content (NJ, SD, MN, ZA, RG). All authors have read and approved the manuscript.

\section{Funding}

This work was supported by the National Institute for Health Research of Islamic Republic of Iran. This paper extracted from results of a research project entitled "Analysis of fiscal space for health in Iran and forecasting it for 2021, 2026 \& 2030" supported by the National Institute for Health Research under contract/ grant number $241 / M / 9658$. The institute provided only financial support for the entire project and did not have any direct contribution in the design of the study, data collection, analysis, and preparation of this manuscript.

\section{Authors' affiliations}

${ }^{1}$ Health Economics, Management and Policy Department, Virtual School of Medical Education \& Management, Shahid Beheshti University of Medical Sciences, Tehran, Iran. ${ }^{2}$ Department of Economics, School of Economics and Political Sciences, Shahid Beheshti University, Tehran, Iran. ${ }^{3}$ Department of Health Management \& Economics, School of Public Health, Tehran University of Medical Sciences, Tehran, Iran. ${ }^{4}$ National Institute of Health Research, Tehran University of Medical Sciences, Tehran, Iran. ${ }^{5}$ Health Services Management Research Center, Institute for Futures Studies in Health, Kerman University of Medical Sciences, Kerman, Iran.

\section{Supplementary files}

Supplementary file 1. Data Sources.

Supplementary file 2. Determining the Variables Cointegration Rank.

Supplementary file 3. Details of Econometric Models.

Supplementary file 4. Validity Assessment.

\section{References}

1. Marmot M, Friel S, Bell R, Houweling TA, Taylor S. Closing the gap in a generation: health equity through action on the social determinants of health. Lancet. 2008;372(9650):1661-1669. doi:10.1016/s01406736(08)61690-6

2. World Health Organization (WHO). Health in 2015: From MDGs, Millennium Development Goals to SDGs, Sustainable Development Goals. Geneva: WHO; 2015.

3. World Health Organization (WHO). Tracking Universal Health Coverage: 2017 Global Monitoring Report. Washington, DC: WHO; 2017.

4. Chu A, Kwon S, Cowley P. Health financing reforms for moving towards universal health coverage in the Western Pacific region. Health Syst Reform. 2019;5(1):32-47. doi:10.1080/23288604.2018.1544029

5. Hurley J, Feeny D, Giacomini M, et al. Introduction to the Concepts and Analytical Tools of Health Sector Reform and Sustainable Financing. Centre for Health Economics and Policy Analysis, McMaster University. 1998.

6. Gottret PE, Schieber G. Health Financing Revisited: A Practitioner's Guide. Washington, DC: The World Bank; 2006.

7. Alipouri Sakha M, Rashidian A, Bazyar M, Akbari Sari A, Yazdani S, Vosoogh-Moghaddam A. Health financing assessment and policy analysis toward universal health coverage: a systematic review of qualitative research. Glob J Health Sci. 2017;9(5):131-142. doi:10.5539/ gjhs.v9n5p131

8. Powell-Jackson T, Hanson K, McIntyre D. Fiscal Space for Health: A Review of the Literature. Resilient and Responsive Health Systems (RESYST) Working Paper. 2012;1.

9. Global Burden of Disease Collaborative Network. Global Expected Health Spending 2018-2050. http://ghdx.healthdata.org/record/ihme-data/ global-expected-health-spending-2018-2050. Accessed May 15, 2020. Published 2020.

10. Thomson S, Foubister T, Figueras J, Kutzin J, Permanand G, Bryndová L. Addressing Financial Sustainability in Health Systems. Copenhagen: WHO Regional Office for Europe; 2009.

11. Constitution of the Islamic Republic of Iran. 1979. https://www.wipo.int edocs/lexdocs/laws/en/ir/ir001en.pdf. Accessed August 3, 2019.

12. Law on the Comprehensive Welfare and Social Security Organizational Structure. http://www.ilo.org/dyn/natlex/natlex4.detail?p_lang=en\&p_ isn=91516\&p_country=IRN\&p_count=168. Accessed August 3, 2019. 
Published 2004

13. Law of the Third Economic, Social and Cultural Development Plan of the Islamic Republic of Iran. Tehran, Islamic Republic of Iran: Islamic Parliament Research Center of the Islamic Republic of Iran; 2000.

14. Law of the Fifth Economic, Social and Cultural Development Plan of the Islamic Republic of Iran. Tehran, Islamic Republic of Iran: Islamic Parliament Research Center of the Islamic Republic of Iran; 2011.

15. Law of the Sixth Economic, Social and Cultural Development Plan of the Islamic Republic of Iran. 2017.

16. Law on the Fourth Economic, Social and Cultural Development Plan of the Islamic Republic of Iran. 2004.

17. Yazdi-Feyzabadi V, Bahrampour M, Rashidian A, Haghdoost AA, Akbari Javar M, Mehrolhassani MH. Prevalence and intensity of catastrophic health care expenditures in Iran from 2008 to 2015: a study on Iranian household income and expenditure survey. Int J Equity Health. 2018; 17(1):44. doi:10.1186/s12939-018-0743-y

18. Abolhallaj M, Hosseini SM, Jafari M, Alaei F. A model for settlement of health insurance organizations' debt to health service delivery institutions. Med J Islam Repub Iran. 2017;31:89. doi:10.14196/mjiri.31.89

19. Doshmangir L, Bazyar M, Najafi B, Haghparast-Bidgoli $H$. Health financing consequences of implementing health transformation plan in Iran: achievements and challenges. Int J Health Policy Manag. 2019;8(6):384386. doi:10.15171/ijhpm.2019.18

20. Moradi T, Naghdi S, Brown H, Ghiasvand H, Mobinizadeh M. Decomposing inequality in financial protection situation in Iran after implementing the health reform plan: what does the evidence show based on national survey of households' budget? Int $\mathrm{J}$ Health Plann Manage. 2018;33(3):652-661. doi:10.1002/hpm.2517

21. Maher A, Fazel Z. Analysis equity in financing of household's health in Iran (by concentration and extended concentration index). Eur J Med Health Sci. 2019;1(1):1-8. doi:10.24018/ejmed.2019.1.1.18

22. Behera DK, Dash U. Effects of economic growth towards government health financing of Indian states: an assessment from a fiscal space perspective. J Asian Public Policy. 2019;12(2):206-227. doi:10.1080/17 516234.2017.1396950

23. World Bank. World Development Indicators/GDP growth rate 2015. http://data. worldbank.org/indicator/NY.GDP.MKTP.KD.ZG?end=2015\&locations=EGIR\&start=1966\&view=map. Accessed April 4, 2017.

24. Central Bank of Islamic Republic of Iran. Economic Time Series Database 2018. https://tsd.cbi.ir/DisplayEn/Content.aspx. Accessed July 5, 2018.

25. Faraji Dizaji S. The effects of oil shocks on government expenditures and government revenues nexus (with an application to Iran's sanctions). Econ Model. 2014;40:299-313. doi:10.1016/j.econmod.2014.04.012

26. Fenochietto R, Pessino C. Understanding Countries' Tax Effort. Washington, DC: International Monetary Fund (IMF); 2013.

27. FayazmaneshS. The politics of the US economic sanctions against Iran. Rev RadicPolitEcon.2003;35(3):221-240. doi:10.1177/0486613403254535

28. Maddah M, Jeyhoon-Tabar F. The tax and petroleum revenue effect on Iran's public expenditures (1994-2015), employing fiscal illusion approach. Iran Econ Rev. 2018;22(3):833-866. doi:10.22059/ier.2018.66646

29. International Monetary Fund (IMF). World Economic Outlook, April 2019: Growth Slowdown, Precarious Recovery. https://www.imf.org/ en/Publications/WEO/Issues/2019/03/28/world-economic-outlookapril-2019. Accessed August 5, 2019.

30. Javanbakht $M$, Jamshidi AR, Baradaran HR, et al. Estimation and prediction of avoidable health care costs of cardiovascular diseases and type 2 diabetes through adequate dairy food consumption: a systematic review and micro simulation modeling study. Arch Iran Med. 2018;21(5):213-222.

31. Stabile $\mathrm{M}$, Thomson $\mathrm{S}$, Allin S, et al. Health care cost containment strategies used in four other high-income countries hold lessons for the United States. Health Aff (Millwood). 2013;32(4):643-652. doi:10.1377/ hlthaff.2012.1252

32. Rezaei S, Fallah R, Kazemi Karyani A, Daroudi R, Zandiyan H, Hajizadeh $M$. Determinants of healthcare expenditures in Iran: evidence from a time series analysis. Med J Islam Repub Iran. 2016;30:313.

33. Chang AY, Cowling K, Micah AE, et al. Past, present, and future of global health financing: a review of development assistance, government, out-of-pocket, and other private spending on health for 195 countries, 1995-2050. Lancet. 2019;393(10187):2233-2260. doi:10.1016/s01406736(19)30841-4

34. Global Burden of Disease Health Financing Collaborator Network. Global
Health Spending 1995-2016. Seattle, United States: Institute for Health Metrics and Evaluation (IHME); 2019.

35. Astolfi R, Lorenzoni L, Oderkirk J. Informing policy makers about future health spending: a comparative analysis of forecasting methods in OECD countries. Health Policy. 2012;107(1):1-10. doi:10.1016/j. healthpol.2012.05.001

36. Dieleman JL, Templin T, Sadat N, et al. National spending on health by source for 184 countries between 2013 and 2040. Lancet. 2016; 387(10037):2521-2535. doi:10.1016/s0140-6736(16)30167-2

37. Dieleman JL, Campbell M, Chapin A, et al. Future and potential spending on health 2015-40: development assistance for health, and government, prepaid private, and out-of-pocket health spending in 184 countries. Lancet. 2017;389(10083):2005-2030. doi:10.1016/s01406736(17)30873-5

38. de la Maisonneuve C, Oliveira Martins J. A Projection Method for Public Health and Long-Term Care Expenditures. Paris: OECD Publishing; 2013. doi:10.1787/5k44v53w5w47-en

39. de la Maisonneuve C, Oliveira Martins J. The future of health and longterm care spending. OECD Journal: Economic Studies. 2015;2014(1):6196. doi:10.1787/eco_studies-2014-5jz0v44s66nw

40. Przywara B. Projecting Future Health Care Expenditure at European Level: Drivers, Methodology and Main Results. Directorate General Economic and Financial Affairs (DG ECFIN), European Commission; 2010.

41. Costa-Font J, Wittenberg R, Patxot C, et al. Projecting long-term care expenditure in four European Union member states: the influence of demographic scenarios. Soc Indic Res. 2008;86(2):303-321. doi:10.1007/ s11205-007-9140-4

42. Pickard L, Comas-Herrera A, Costa-Font J, et al. Modelling an entitlement to long-term care services for older people in Europe: projections for long-term care expenditure to 2050. J Eur Soc Policy. 2007;17(1):33-48. doi:10.1177/0958928707071879

43. Klazoglou P, Dritsakis N. Modeling and forecasting of US health expenditures using ARIMA models. In: Tsounis N, Vlachvei A, eds. International Conference on Applied Economics. Cham: Springer; 2017: 457-472. doi:10.1007/978-3-319-70055-7_36

44. Cuckler GA, Sisko AM, Poisal JA, et al. National health expenditure projections, 2017-26: despite uncertainty, fundamentals primarily drive spending growth. Health Aff (Millwood). 2018;37(3):482-492. doi:10.1377/ hlthaff.2017.1655

45. Vos T, Goss J, Begg S, Mann N. Projection of Health Care Expenditure by Disease: A Case Study from Australia. United Nations; 2007.

46. Fukawa T. Elderly population projection and their health expenditure prospects in Japan. Mod Econ. 2017;8(11):1258-1271. doi:10.4236/ me.2017.811085

47. Lorenzoni L, Morgan D, Murakami Y, James C. Public Expenditure Projections for Health and Long-Term Care for China Until 2030. Paris: OECD Publishing; 2015. doi:10.1787/5jrs3c274vq3-en

48. Lee $\mathrm{C}$, Kwon $\mathrm{H}$, Chae J. A financial projection of health insurance expenditures reflecting changes in demographic structure. J Korean Public Health Nurs. 2017;31(1):5-18. doi:10.5932/jkphn.2017.31.1.5

49. Xu K, Soucat A, Kutzin J, et al. New Perspectives on Global Health Spending for Universal Health Coverage. Geneva: World Health Organization; 2017.

50. United Nations DoEaSA. World Population Prospects: The 2017 Revision. 2017. https://esa.un.org/unpd/wpp/Download/Standard/Mortality/. Accessed July 2, 2018.

51. Rezaeian M, Dunn G, St Leger S, Appleby L. Geographical epidemiology, spatial analysis and geographical information systems: a multidisciplinary glossary. J Epidemiol Community Health. 2007;61(2):98-102. doi:10.1136/ jech.2005.043117

52. US. Energy Information Administration (EIA). Annual Energy Outlook 2018. https://www.eia.gov/outlooks/aeo/tables_side.php. Accessed January 27, 2019.

53. Institute for Health Metrics and Evaluation (IHME). Financing Global Health Visualization. 2020. http://vizhub.healthdata.org/fgh/\%E2\%80\%8B. Accessed May 15, 2020.

54. Turgut M, Ağırbaş İ, Aldoğan U. Relationship between health expenditure and inflation in Turkey. Akademik Sosyal Araştırmalar Dergisi. 2017;5(50):289-299.

55. Gil-Alana LA, Dadgar Y, Nazari R. Iranian inflation: peristence and structural breaks. Journal of Economics and Finance. 2019;43(2):398- 
408. doi:10.1007/s12197-018-9446-x

56. Sharif M, Hojabri R, Saidpour J, Rahimpour Langroudi H. Inflation and financing of commercial insurance in the field of treatment. Evidence Based Health Policy, Management \& Economics. 2018;2(3):144-155.

57. Teimourizad A, Hadian M, Rezaei S, Homaie Rad E. Health sector inflation rate and its determinants in Iran: a longitudinal study (1995-2008). Iran J Public Health. 2014;43(11):1537-1543.

58. Yagihashi T, Du J. Health care inflation and its implications for monetary policy. Econ Inq. 2015;53(3):1556-1579. doi:10.1111/ecin.12204

59. World Health Organization (WHO). World Health Statistics 2015. Geneva: WHO; 2015.

60. Hartwig J. What drives health care expenditure?--Baumol's model of 'unbalanced growth' revisited. J Health Econ. 2008;27(3):603-623. doi:10.1016/j.jhealeco.2007.05.006

61. Smith S, Newhouse JP, Freeland MS. Income, insurance, and technology: why does health spending outpace economic growth? Health Aff (Millwood). 2009;28(5):1276-1284. doi:10.1377/hlthaff.28.5.1276

62. Jakovljevic M, Getzen TE. Growth of global health spending share in low and middle income countries. Front Pharmacol. 2016;7:21. doi:10.3389/ fphar.2016.00021

63. Rezaei S, Fallah R, Moradi K, Delavari S, Doost Moradi S, Karami Matin B. Macro determinants of Iranian provincial healthcare expenditures from 2006 to 2013: evidence from panel data. Electron Physician. 2015; 7(8):1584-1589. doi:10.19082/1584

64. Masoudi AsI I, Bakhtiari Aliabad M, Akhavan Behbahani A, Rahbari Bonab M. Health system costs in Iran, how to manage it. Iran Health Insurance Organization. 2019;1(4):117-127.

65. Mohtasham F, Yazdizadeh B, Zali Z, Majdzadeh R, Nedjat S. Health technology assessment in Iran: barriers and solutions. Med J Islam Repub Iran. 2016;30:321.

66. Cashin C, Bloom D, Sparkes S, Barroy H, Kutzin J, O'Dougherty S. Aligning Public Financial Management and Health Financing: Sustaining Progress Toward Universal Health Coverage. Geneva: World Health Organization; 2017

67. Mclntyre D, Kutzin J. Health Financing Country Diagnostic: A Foundation for National Strategy Development. Geneva: World Health Organization; 2016.

68. International Monetary Fund. World Economic Outlook (October 2018). https://www.imf.org/external/error.htm?URL=https://www.imf.org/en/
Publications/SPROLLs-GSA/world-economic-outlook-databases. Accessed June 21, 2018.

69. Atashbar T, Ghasemi M, Zamani R. Sustainability of public financial obligations of Iran in the medium term. Tehran: Islamic Consultative Research Bureau: Public Sector Studies Office; 2016.

70. Saleh K, Couttolenc BF, Barroy H. Health Financing in the Republic of Gabon. Washington, DC: The World Bank; 2014.

71. Barroy $\mathrm{H}$, Kutzin J, Tandon A, et al. Assessing fiscal space for health in the SDG era: a different story. Health Syst Reform. 2018;4(1):4-7. doi:10.108 0/23288604.2017.1395503

72. Takian A, Firoozeh B, Akbari Sari A, Harirchi I. Analysis for Policy to Develop Policy Options to Increase Fiscal Space for Health System in Iran [Thesis]. Tehran: Tehran University of Medical Sciences; 2018. [Persian].

73. Grasselli G, Greco M, Zanella A, et al. Risk factors associated with mortality among patients with COVID-19 in intensive care units in Lombardy, Italy. JAMA Intern Med. 2020;180(10):1345-1355. doi:10.1001/ jamainternmed.2020.3539

74. Davari M, Haycox A, Walley T. The Iranian health insurance system; past experiences, present challenges and future strategies. Iran J Public Health. 2012;41(9):1-9.

75. Ibrahimipour H, Maleki MR, Brown R, Gohari M, Karimi I, Dehnavieh R. A qualitative study of the difficulties in reaching sustainable universal health insurance coverage in Iran. Health Policy Plan. 2011;26(6):485-495. doi:10.1093/heapol/czq084

76. Akhavan Behbahani A, Mousavi Khatat M, Manuchehr N, Masoumeh $\mathrm{R}$, Maleki M. Reviewing the status of the Social Security Organization and the need for fundamental reforms in it (Immediate measures required). Tehran: Office of Social Studies Research Center of the Islamic Consultative Assembly; 2017. [Persian].

77. World Health Organization (WHO). Regulation Private Health Insurance to Serve the Public Interest: Policy Issues for Developing Countries. Geneva: WHO; 2005.

78. Homaie Rad E, Kavosi Z, Moghadamnia MT, Arefnezhad M, Arefnezhad M, Felezi Nasiri B. Complementary health insurance, out- of- pocket expenditures, and health services utilization: a population- based survey. Med J Islam Repub Iran. 2017;31:59. doi:10.14196/mjiri.31.59

79. Sekhri N, Savedoff W. Private health insurance: implications for developing countries. Bull World Health Organ. 2005;83(2):127-134. 